\title{
The Effect of Temperature and Body Size on Filtration Rates of Limnoperna Fortunei (Bivalvia, Mytilidae) under Laboratory Conditions
}

\author{
Débora Pestana $^{3 *}$, Antonio Ostrensky ${ }^{1,3}$, Walter Antonio Pereira Boeger ${ }^{2,}{ }^{3}$, Marcio \\ Roberto Pie ${ }^{3}$ \\ ${ }^{I}$ Departamento de Zootecnia; Universidade Federal do Paraná; Curitiba - PR - Brasil. ${ }^{2}$ Departamento de Zoologia; \\ Universidade Federal do Paraná; Curitiba - PR - Brasil. ${ }^{3}$ Grupo Integrado de Aqüicultura e Estudos Ambientais; \\ Universidade Federal do Paraná; C.P.: 19073; 81531-990; Curitiba - PR - Brasil
}

\begin{abstract}
The golden mussel (Limnoperna fortunei, Mollusca: Bivalvia) is an invasive species that has been causing considerable environmental and economic problems in South America. In the present study, filtration rates of L. fortunei were determined in the laboratory under different temperatures $\left(10,15,20,25,28\right.$, and $\left.30{ }^{\circ} \mathrm{C}\right)$ and two types of food (Algamac-2000 ${ }^{\circledR}$ and the chlorophycean alga Scenedesmus sp.). There was a statistically significant relationship between time and filtration rates in the experiment using Scenedesmus sp., regardless of temperature. However, this pattern was absent in the experiment using Algamac, suggesting that the relationship between filtration rates and temperature might depend on the size of the filtered particles. In addition, there was no correlation between filtration rates and either shell size or condition index (the relationship between the weight and the length of a mussel). The filtration rate measured in the present study $(724.94 \mathrm{ml} / \mathrm{h})$ was one of the highest rates recorded among invasive bivalves to date. Given that the colonies of the golden mussel could reach hundreds of thousands of individuals per square meter, such filtration levels could severely impact the freshwater environments in its introduced range.
\end{abstract}

Key words: invasive species, condition index, Scenedesmus sp., Algamac-2000®, environmental impact

\section{INTRODUCTION}

Limnoperna fortunei (the golden mussel) is a bivalve from southeast China that has been spreading its distribution by invading other regions of the world, particularly through the transport in the ballast water of large vessels. This was the likely source for the introduction of the golden mussel to South America in the Rio de la Plata basin around 1991 (Darrigran et al. Pastorino,
1995). Since then, L. fortunei has already colonized the entire Rio Paraguay $(1,718 \mathrm{~km})$ and reached the Brazilian states of Mato Grosso do Sul, São Paulo and Paraná (Oliveira et al, 2004). In Porto Alegre (RS), where the golden mussel has been detected since 1998, this species has already colonized lake Guaíba, causing incrustrations to water supply facilities.

The capacity to form enormous aggregates of up to 150,000 individuals $/ \mathrm{m}^{2}$ (Cataldo et al., 2002) has

\footnotetext{
* Author for correspondence: deborapestana14@yahoo.com.br
} 
caused this species to exert severe negative environmental and economic impacts in its introduced range. Although there are individuals of virtually all size classes in large aggregates of $L$. fortune $i$, there are times of the year when more than $70 \%$ of the individuals in these aggregates are smaller than $2 \mathrm{~mm}$ (Boltovskoy et al. Cataldo, 1999).

In addition to the economic impacts associated with the clogging of pipes in industrial and hydroelectric power plants, common environmental impacts of the golden mussel include significant changes in fish (Montaldo et al., 1999) and benthic faunas (Darrigran et al., 1998), as well as in the dynamics of nutrient and pollutant cycling in freshwater environments (Porta, 2001). Large aggregates of L. fortunei can alter substantially the trophic structure of aquatic ecosystems by the filtration of suspended material (seston) and the deposition of this material in the form of feces or pseudofeces (Lei et al., 1996).

Despite the substantial impact of the golden mussel on natural habitats, little is known about the biology of this species in South America. Given that many of those impacts result from its filter-feeding habits, it is crucial to understand the filtering dynamics of this species. Filtration rates can vary considerably among bivalves, with previous reports varying from 347 to $567 \mathrm{~mL} / \mathrm{h} / \mathrm{ind}$ in Corbicula sp. (Buttner and Heindinger 1981, Way et al. 1990, Silverman et al. 1997), from 40 to $375 \mathrm{~mL} / \mathrm{h} / \mathrm{ind}$ in Dreissena polymorpha (Reeders et al. 1989, Sprung 1995, Berg et al. 1996, Horgan and Mills 1997, Diggins 2001), from 200 to 310 $375 \mathrm{~mL} / \mathrm{h} / \mathrm{ind}$ in Dreissena bugensis and between 133 to $350 \mathrm{~mL} / \mathrm{h} / \mathrm{ind}$. in Limnoperna fortunei. The goal of the present study was to assess the effects of temperature and body size on filtration rates of L. fortunei under laboratory conditions.

\section{MATERIALS AND METHODS}

\section{Collection and maintenance of the golden mussel in the laboratory}

Specimens were collected on several occasions between June 2003 and October 2005. Individuals were manually removed from the water inlets and platforms of the reservoir of the Itaipu hydroelectric power plant located in the municipality of Foz do Iguaçu, State of Paraná, Southern Brazil. In the laboratory, mussels were kept in $130 \mathrm{~L}$ aquaria equipped with plastic meshes that were used for their attachment, filtered dechlorinated water, constant temperature $\left(20^{\circ} \mathrm{C}\right)$ and $\mathrm{pH}$ (7.4), and a $12 \mathrm{~h}: 12 \mathrm{~h}$ light/dark photoperiod. The aquaria were kept in a biological filtering system and with constant supplementary, aeration. These conditions were chosen as to emulate to the extent possible the conditions were the animals were collected.

Whenever the specimens were not in experiments, food was provided three times a day as a solution containing three species of algae: Chlorella sp. (Chlorophyceae - Chlorococcales) and Spirulina sp (Cyanobacteriae - Oscillatoriales), which had been previously dehydrated and then dissolved in dechlorinated water, and Scenedesmus sp. (Chlorophyceae - Chlorococcales). The latter was found in the digestive tract of field collected individuals of $L$. fortunei (unpublished results). Only two types of food were provided during the experiments: Algamac-2000®, a commercial food composed of dehydrated cells of the microalga Schizochytrium sp. (Thraustochytriaceae), commonly used in the cultivation of aquatic organisms, and algae of the genus Scenedesmus, specially cultivated for this goal.

\section{Experiments using Algamac-2000 ${ }^{\circledR}$}

Prior to each experiment, animals $(>15 \mathrm{~mm})$ were removed from the rearing aquaria, had their length measured using a digital caliper, and were placed in numbered containers with filtered dechlorinated water. Only individuals with filtering activity, as evidenced by the partial exposition of their mantle were used in experiments to insure that they were in good health. These containers were kept in the environmental chambers with constant temperature and photoperiod (12h: $12 \mathrm{~h}$ light/dark) and continuous aeration, where they remained for $24 \mathrm{~h}$ without receiving any food. Each batch included 20 containers, two mussels each, and five control containers without any mussel.

The same number of containers, each with $450 \mathrm{ml}$ of dechlorinated filtered water but without any mussel, was placed in the environmental chamber, simultaneously to the acclimatizing of the animals so that all containers had in the same temperature by the time of the transfer of the mussels. On the next day, $50 \mathrm{ml}$ of the food stock solution was added to these containers. The solutions of Algamac-2000 ${ }^{\circledR}$ were arranged by preparing a solution of this alga in dechlorinated filtered water such that the final solution where the mussels were kept was around $0.1 \mathrm{~g}$ of algae/l. Aliquots were 
obtained from all 25 containers to measure the initial concentration of algal cells used as food. The mussels were then transferred to the numbered containers, which were returned immediately to the environmental chamber.

Aliquots for the assessment of the algal concentrations in the containers were taken $1,2,3$, 6 and $24 \mathrm{~h}$ after the initial contact between the mussels and their food using a digital spectrophotometer at $640 \mathrm{~nm}$. The recorded transmittance values were transformed into food concentration $(\mathrm{g} / \mathrm{l})$ using previously established standard curves.

\section{Experiments using Scenedesmus (Chlorophyceae - Chlorococcales)}

The Scenedesmus sp. algae used in the experiments were also collected in the Itaipu Reservoir. The algae were cultured in 201 plastic containers using the Conway culture medium (Barbieri and Ostrensky, 2001). After around seven days, the culture was transferred to larger containers $(100$ l) with dechlorinated filtered water. Macrofertilizers were added to these containers (urea and triple superphosphate). The Scenedesmus sp. culture was regularly filtered through a $5 \mu \mathrm{m}$ mesh size and washed to eliminate the excess of nitrogenated wastes resulting from the culture medium.

The experimental design followed the same model as the experiments conducted with the Algamac2000 囚. Aliquots were taken after 1, 2, and $3 \mathrm{~h}$ after the first contact with the animals, also being analyzed using a digital spectrophotometer at 720 $\mathrm{nm}$, the most appropriate wavelength to detect the green algae (Aldridge et al.,1995). Transmittance values of the solution containing the food were transformed into concentration (number of cells/ml) using standard curves. The initial concentrations of the stock solutions of these algae were obtained by the cell counting using a hemocytometer and varied between $30 \times 10^{4}$ and $70 \times 10^{4}$ cells/ the $\mathrm{ml}$. These concentrations were higher than those normally used in this type of experiment. Although this cause the present results not to be easily comparable to other similar studies, such higher concentrations should enhance the effects of body size and particle size which were the focus of the present study.

\section{Condition index}

At the end of the experiments, each mussel was removed from its shell by sectioning the abductor muscle, placed in an incubator for $14 \mathrm{~h}$ at $60^{\circ} \mathrm{C}$ and weighted with a digital balance to calculate their condition index (CI). The CI describes the relationship between the weight and the length of each individual. In the present study, the CIs were based on Fulton's index (Mgaya et al. Mercer, 1995) as the dry weight in $\mathrm{g}$ times $10^{6}$ and divided by the length in $\mathrm{mm}$.

\section{Calculation of filtration rates}

The indirect method was used in the present study to calculate the filtration rates of the golden mussel, given that it was both reliable and simple in its experimental design (see Riisgard, 2001 for a review). However, a disadvantage of this method was the fact that the measurement of the food concentration tended to decrease naturally over time due to the tendency towards the sedimentation of the algae to the bottom of the container. To avoid this bias in the results, the concentrations in the experimental containers were compared with the ones that received the same solution but lacked the mussels. Once the food concentration values were obtained, the Coughlan (1969) equation was used to calculate the filtration rate:

$$
F=\frac{V}{n t}\left[\left(C-C_{0}\right)-\left(C^{\prime}-C_{0}^{\prime}\right)\right]
$$

Where $F$ is the individual filtering rate (volume/individual/h) or $\mathrm{ml} / \mathrm{h}, V$ is the volume of the container, $n$ is the number of individuals in the container, $t$ is the duration of the experiment in hours, $C$ and $C_{0}$ are the natural logarithms of the initial and final concentration of algae in the experimental containers, and $C^{\prime}$ and $C_{0}^{\prime}$ are natural logarithms of the initial and final concentration of algae in the control containers (without mussels), respectively. The filtration rate can be defined as the volume of water that passes through the branchiae of the mussel at a given time interval (Lei et al., 1996). In the present study, the filtration rate unit is $\mathrm{ml} / \mathrm{mussel} / \mathrm{h}$.

Experiments using Algamac-2000 @ were conducted under the following temperatures: 10 , $15,20,25,28$, and $30^{\circ} \mathrm{C}$, whereas experiments using Scenedesmus sp. were conducted at 15, 20, 
and $25^{\circ} \mathrm{C}$. Given that the data obtained in the experiments departed significantly from a normal distribution (Shapiro-Wilk's test), the analyses were carried out using the sample medians in the Kruskall-Wallis test and gamma correlations as implemented in the software Statistica 6.0 (StatSoft Inc., 2003).

\section{RESULTS}

Although an ensemble analysis of all the data indicated a statistically significant correlation between the temperature and filtration rates when Algamac-2000® was used as the food source $(\mathrm{N}=773$ measurements, $\mathrm{p}<0.05)$, the magnitude of that correlation was poor $(\gamma=0.12)$. Moreover, a comparison between different temperature classes indicated that the only class that showed significant departures from the other classes was $30^{\circ} \mathrm{C}$ (Kruskal-Wallis ANOVA, $\mathrm{H}_{(5, \mathrm{~N}=773)}=38.9$, $\mathrm{p}<0.001)$. The single apparent trend in the relationship between the temperature and filtration rates seemed to be an increase in the filtration variability under higher temperatures (Figure 1).

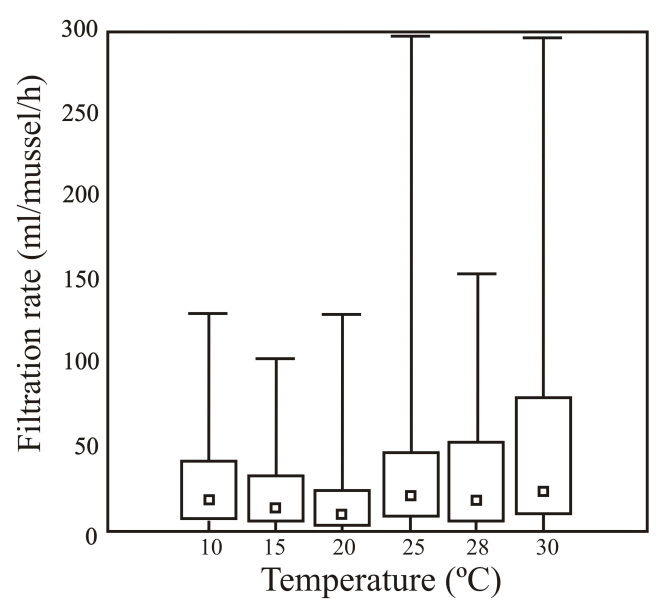

Figure 1 - Filtration rates of Algamac-2000 @ by Limnoperna fortunei in different temperatures throughout the $24 \mathrm{~h}$ of the experiment. Sample sizes for each temperature class were: $10^{\circ} \mathrm{C}, \mathrm{N}=116 ; 15^{\circ} \mathrm{C}, \mathrm{N}=92 ; 20^{\circ} \mathrm{C}, \mathrm{N}=135 ; 25^{\circ} \mathrm{C}, \mathrm{N}=195 ; 28^{\circ} \mathrm{C}, \mathrm{N}=107 ; 30^{\circ} \mathrm{C}, \mathrm{N}=128$. Error bars represent the observed range, box limits indicate the $25 \%-75 \%$ range and the inner symbol indicates the median.

On the other hand, there was a clear temporal shift in the filtration rates. When all the temperatures were tested simultaneously, there was a statistically significant negative correlation between the time and filtration rates $(\gamma=0.46$, $\mathrm{P}<0.005)$. However, when different temperature classes were tested separately (Figure 2), correlation coefficients differed in magnitude, with the largest coefficient being obtained for the $15^{\circ} \mathrm{C}$ temperature class $(\gamma=-0.69)$ and the smallest for the $25^{\circ} \mathrm{C}$ and $30^{\circ} \mathrm{C}$ classes $(\gamma=-0.33)$. The remaining coefficients were: at $10^{\circ} \mathrm{C}, \gamma=-0.42$, at $20^{\circ} \mathrm{C}, \gamma=-0.46$, and at $28^{\circ} \mathrm{C}, \gamma=-0.53$. The highest filtration rates were recorded under $25^{\circ} \mathrm{C}(297$ $\mathrm{ml} / \mathrm{mussel} / \mathrm{h})$ and $30^{\circ} \mathrm{C}(295.7 \mathrm{ml} / \mathrm{mussel} / \mathrm{h})$, with both values being recorded in the first hour of the experiment (Figure 2).
Experiments carried out using Scenedesmus sp. as food showed results that were rather different from those using Algamac $-2000^{\circledR}$. When feeding on Scenedesmus, not only the temperature influenced consistently the filtration rates in L. fortunei, but the rates themselves were much larger than in previous experiments $(\mathrm{N}=131$ measurements, $\gamma=0.52, p<0.000001$, Figure 3). In addition, the increase in filtration rates with the temperature was consistent, either when all the groups were analyzed together, or when rates were calculated separately for each time period $\left(1^{\text {st }}\right.$ hour: $\mathrm{N}=39$; $\gamma=0.55 ; \mathrm{p}=0.000056 ; 2^{\text {nd }}$. Hour: $\mathrm{N}=45 ; \gamma=0.60 ; \mathrm{p}=$ $0.000002 ; 3^{\text {rd }}$. hour: $\left.\mathrm{N}=47 ; \gamma=0.42 ; \mathrm{p}=0.00064\right)$.

There was a poor correspondence between filtration rates and either condition indices (CIs) and shell lengths, a pattern that was consistent in 
both food types (Table 1). In particular, even though the gamma correlation was often statistically significant, the gamma correlation coefficients were very low, not exceeding 0.12 .
These results indicated that the variation in body size did not seem to be a strong modulator of filtering rates.

Table 1 - Results of gamma correlation analysis to assess how filtration rates covary with condition index and shell length.

\begin{tabular}{ccccc}
\hline Food type & Variable tested against filtration rate & gamma & $\mathbf{p}$ & $\mathbf{N}$ \\
\hline Algamac-2000® & shell length & -0.09 & 0.0015 & 773 \\
Scenedesmus sp. & condition index & 0.12 & 0.029 & 131 \\
Scenedesmus sp. & shell length & 0.06 & 0.06 & 131 \\
\hline
\end{tabular}
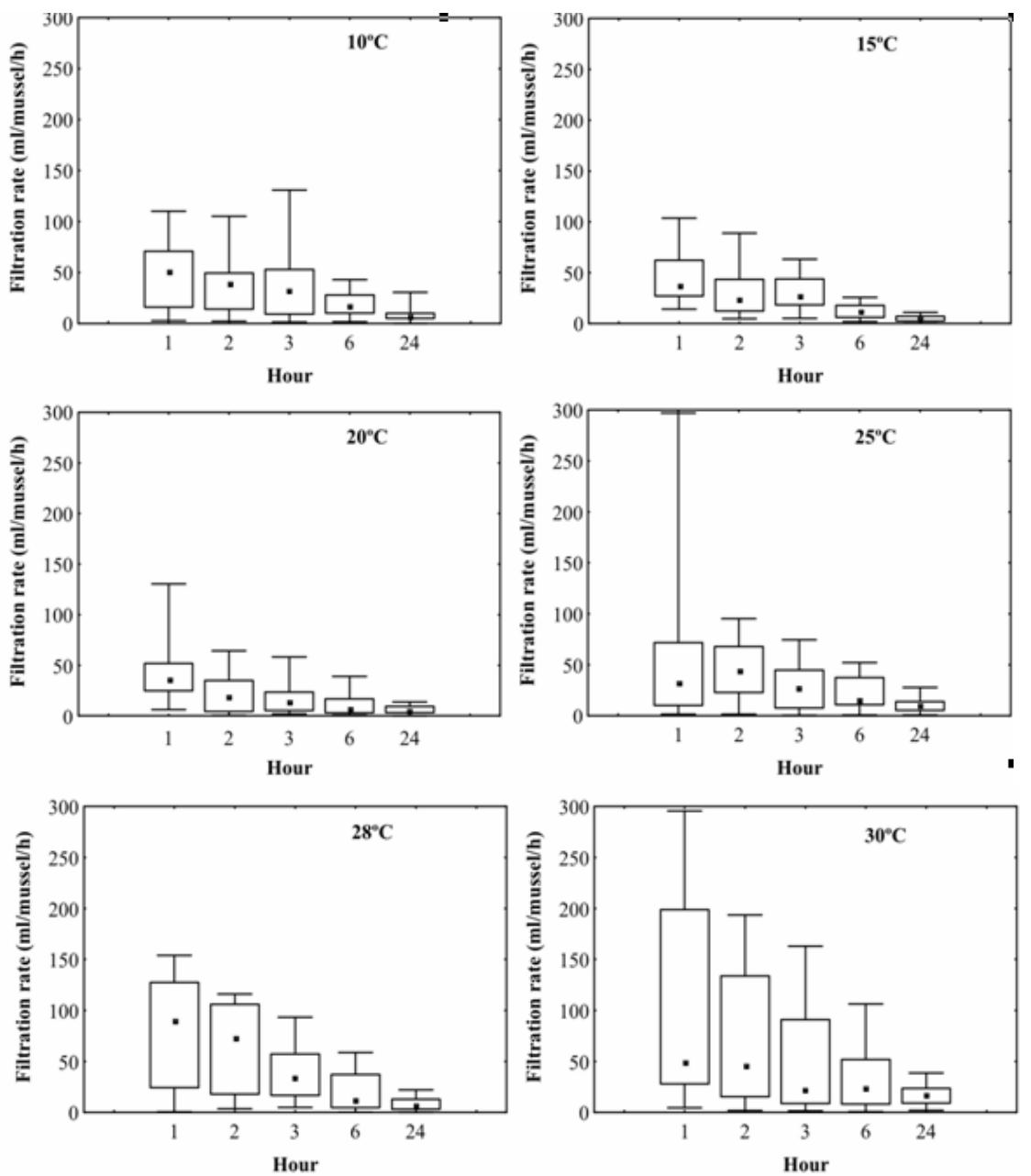

Figure 2 - Filtration rates of algamac-2000® by Limnoperna fortunei under different temperatures and over time. Error bars represent the observed ranger, box limits indicate the 25\%$75 \%$ range and the inner symbol indicates the median. 

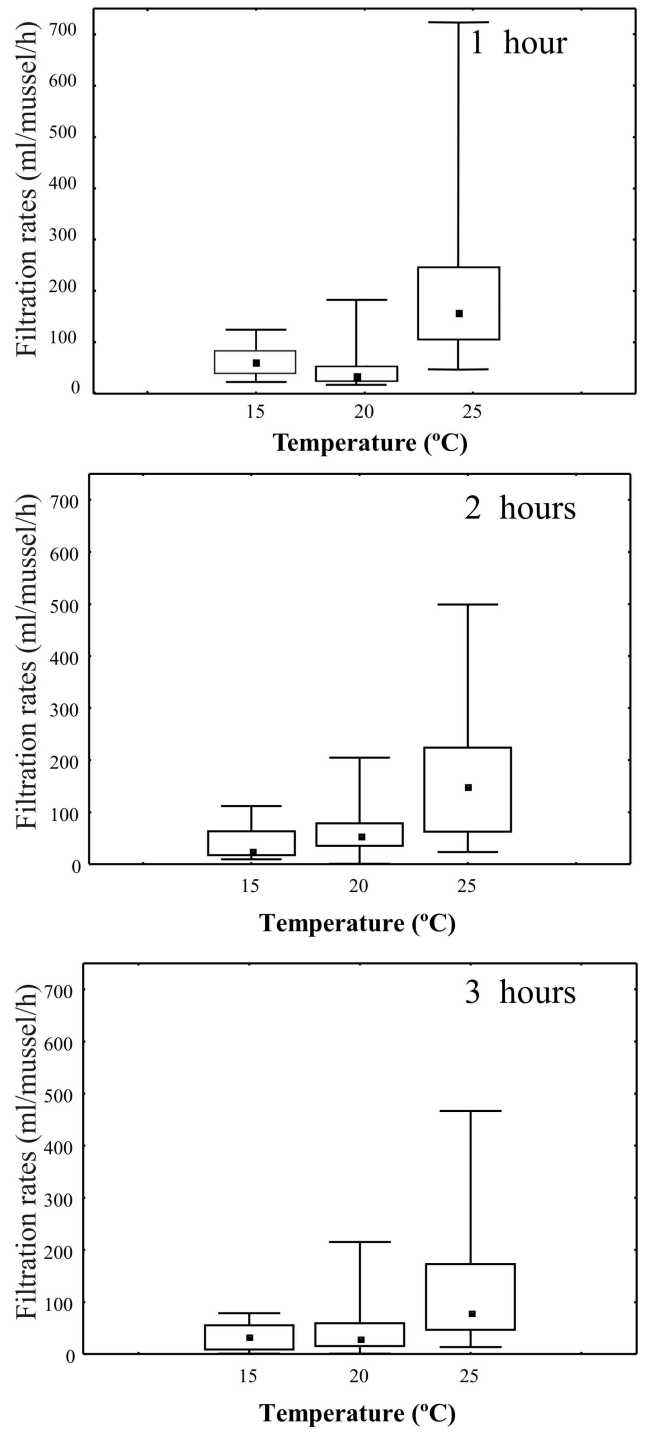

Figure 3 - Filtration rates of Scenedesmus sp. by L. fortunei under different temperatures and over time. Error bars represent the observed range, box limits indicate the $25 \%-75 \%$ range and the inner symbol indicates the median.
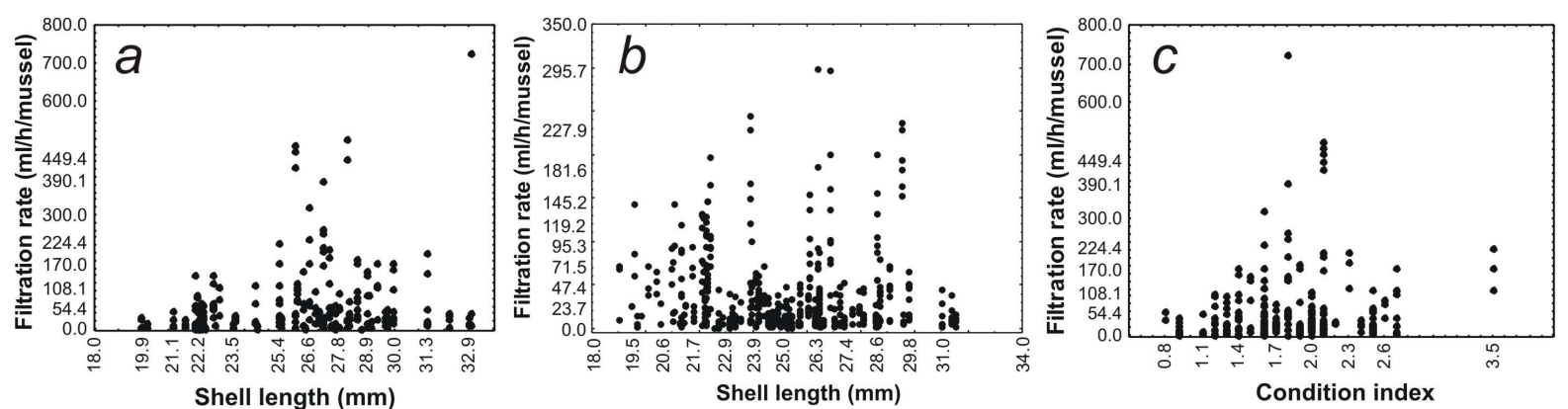

Figure 4 - Filtration rate of Scenedesmus sp. (a,c) and Algamac-2000® (b) by L. fortunei.in relation to shell length $(a, b)$ and condition index $(c)$. 


\section{DISCUSSION}

\section{Filtration rates}

There was a tendency towards a decrease in the filtration rates of $L$. fortunei over time during the experiments. Two factors could explain this tendency: the satiation of the mussels and the decrease in the concentration of available food, with the latter being more likely. According to Higgins (1980) and Horgan et al. Mills (1997), there was a positive correlation between the amount of the food available and filtration rates.
This strategy could optimize the energy spent during the filtration activities, which increases asymptotically with the concentration of available food particles (Savina and Pouvreau, 2004). Moreover, it is of great ecological relevance given that the golden mussel forms aggregations of thousands of individuals which can deplete the seston in invaded sites. Interestingly, according to the data presented by Sylvester et al. (2005), the filtration rates recorded in the present study for $L$. fortunei were among the highest ever recorded for invasive bivalves (Table 2).

Table 2 - Filtration rates of invasive bivalves (adaptaded from Sylvester et al., 2005 and Von Rückert, 2004).

\begin{tabular}{|c|c|c|}
\hline Species / tested temperature & Reference & $\begin{array}{c}\text { Maximum filtration rate } \\
(\mathrm{mL} / \mathrm{h} / \text { individual })\end{array}$ \\
\hline \multicolumn{3}{|l|}{ Corbicula $\mathrm{sp}$} \\
\hline $21-24{ }^{0} \mathrm{C}$ & Buttner and Heindinger (1981) & 347 \\
\hline $22^{0} \mathrm{C}$ & Silverman et al.1997 & 489.5 \\
\hline $15{ }^{0} \mathrm{C}$ & Way et al. (1990) & 567 \\
\hline \multicolumn{3}{|l|}{ Dreissena polymorpha } \\
\hline $22{ }^{0} \mathrm{C}$ & Berg et al. (1996) & 40 \\
\hline $22{ }^{0} \mathrm{C}$ & Berg et al.(1996) & 125 \\
\hline $8-22{ }^{0} \mathrm{C}$ & Diggins (2001) & 170 \\
\hline $13-17^{0} \mathrm{C}$ & Reeders et al (1989) & 170 \\
\hline $8-22{ }^{0} \mathrm{C}$ & Diggins (2001) & 225 \\
\hline $17{ }^{0} \mathrm{C}$ & Horgan and Mills (1997) & 223 \\
\hline $24{ }^{0} \mathrm{C}$ & Sprung (1995) & 375 \\
\hline \multicolumn{3}{|l|}{ Dreissena bugensis } \\
\hline $8-22{ }^{0} \mathrm{C}$ & Diggins (2001) & 200 \\
\hline $8-22{ }^{0} \mathrm{C}$ & Diggins (2001) & 310 \\
\hline \multicolumn{3}{|l|}{ Limnoperna fortunei } \\
\hline $23.5-24.5^{0} \mathrm{C}$ & Von Rückert (2004) & 133.75 \\
\hline $15-25{ }^{0} \mathrm{C}$ & Sylvester et al (2005) & 350 \\
\hline $10-30{ }^{0} \mathrm{C}($ Algamac-2000®) & Presente trabalho & 297 \\
\hline $15-20{ }^{\circ} \mathrm{C}$ (Scenedesmus sp) & Presente trabalho & 725 \\
\hline
\end{tabular}

The discrepancies between the values obtained in the only three studies that quantified filtration rates in L. fortunei (Von Rückert et al. 2004, Sylvester et al. 2005 andthe present study) were probably due to the methodological differences, particularly with respect to their experimental design and the type of food (cyanobacteria; Chlorella sp.; Algamac-2000® and Scenedesmus sp., respectively). However, despite those differences, there was a concordance between these studies in that the filtering activities of $L$. fortunei were capable of causing considerable impact on invaded ecosystems.

\section{The Relationship Between Filtration Rates And Temperature}

There was a positive relationship between the filtration rates and temperature in the experiments using Scenedesmus sp. as the food source, yet this relationship was inconsistent in the experiments that used Algamac-2000 ${ }^{\circledR}$. Given that Scenedesmus sp. particles were much smaller than those in the Algamac solution (see below), this result might indicate that the relationship between the filtration rates and temperature depended on the size of the filtered particles, being more efficient in the case of smaller cells such as those found in Scenedesmus sp.. 
The continuation of filtering activities over a wide range of temperatures was consistent with the fact that $L$. fortunei was a eurythermic species, supporting the temperature variation in nature between 8 and $32^{\circ} \mathrm{C}$ (Ricciardi, 1996). Variation between 8 and $18^{\circ} \mathrm{C}$ also did not show a detectable influence on the respiratory activity and filtering rates of Paphia rhomboids and Glycymeris glycimeris (Savina and Pouvreau, 2004). In order to get established and to dominate a new environment, invasive species must possess high physiological flexibility. Reeders and. bij de Vaate (1990) showed that the filtering rate of another invasive bivalve, Dreissena polymorpha, was unaffected by the temperature variation between 5 and $20^{\circ} \mathrm{C}$, although lower temperatures nearly caused the filtering activities to cease. The same authors, in 1992, analyzing the impact of pollutant material in suspension concluded that the water temperature played a minor role on the filtration rates, and that the amount of material in suspension was more important in modulating filtration. Fanslow et al. (1995), studying the same species in the Saginaw Bay (Great Lakes region), concluded that the maximum filtration levels were probably associated with the temperature, although indirectly, through a decrease in seston and consequent increase in the filtration rates. On the other hand, Aldridge et al. (1995) did detect a negative relationship between the temperature and filtration rates in $D$. polymorpha, with filtration rates at $20-24^{\circ} \mathrm{C}$ being significantly higher than at $28-30^{\circ} \mathrm{C}$. This result could be accounted for by the fact that the highest water temperatures in that region during summer did not exceed $24.5^{\circ} \mathrm{C}$.

In the only other study that investigated the relationship between the filtration rate and temperature in L. fortunei, Sylvester et al. (2005) tested three temperatures $\left(15,20\right.$ and $\left.25^{\circ} \mathrm{C}\right)$, with the highest rate found at $15^{\circ} \mathrm{C}$. The results obtained in the present study indicated that the filtration rates in $L$. fortunei were largely unaffected by temperature, suggesting that the impact from its feeding activities might be relatively constant throughout the year.

\section{Filtration rates, body size and condition index}

The condition index (CI) is an indication of the physiological state of the bivalve and is directly proportional to the amount of stored energy. Therefore, this quantity is frequently used to characterize the health of an organism given the local environmental conditions (Beninger et al.
Lucas, 1984). The weak association between the filtration rates and either $\mathrm{CI}$ and body size indicated that the individuals belonging to the studied size class $(>15 \mathrm{~mm})$, regardless of their size, could provide similar impacts through their filtration activities. This result disagreed with most studies that related the body size or biomass with the filtration rates in the zebra mussel (Dreissena polymorpha) (e.g. Reeders and Bij de Vaate, 1990, Berg et al., 1996) as well as in many bivalves (Bougrier et al., 1995). Such poor association in the case of the golden mussel has also been observed by Sylvester et al. (2005), which was statistically significant only at $20^{\circ} \mathrm{C}$. It was unlikely that these results were artifactual given the large sample sizes used in the present experiments ( 773 individuals in the experiments using Algamac ${ }^{\circledR}$ and 131 in the experiments using Scenedesmus sp., as opposed to 14-20 individuals/experiment in the study by Sylvester et al.). However, there seemed to be considerable variability in filtration rates among individuals, even within each size class.

\section{Filtration rates and particle size}

The differences in filtration rates between the different types of food used in the present study (Algamac-2000® and Scenedesmus sp.) could be accounted for by the differences in algal cell size. Although both were composed of colonial algae, cell size in Schizochytrium sp. (Algamac-2000®) was about twice that of Scenedesmus $(10 \mu \mathrm{m}$ versus $5 \mu \mathrm{m}$, respectively). Moreover, the cell aggregates were larger in Schizochytrium, at times exceeding $100 \mu \mathrm{m}$, as opposed to $40 \mu \mathrm{m}$ in the case of Scenedesmus sp. (unpublished data). Particle size has been known to play an important role in modulating filtration rates in bivalves (see Ward et al. Shumway, 2004 for a review). For instance, freshwater species are more effective in filtrating small particles than their marine counterparts (Lei et al., 1996).

Baker et al. (1998) and Vanderploeg et al., Nalepa (2001) detected shifts in local phytoplanktonic communities following the introduction of the zebra mussel (D. polymorpha). The mechanism underlying those shifts seemed to be the selective removal of particles of specific sizes, with the rejected particles being returned to the water column in the form of unconsolidated pseudofeces. Vanderploeg et al. (2001) suggested that the blooms of the toxic cyanobacterium Microcystis aeruginosa in the Saginaw bay might have 
resulted from the filtering activities of the zebra mussel.

Therefore, the selectivity in the filtration of particles by $L$. fortunei observed in the present study could cause important shifts in its local environments, possibly by increasing the dominance of certain phytoplanktonic species. This result was particularly troubling given that the highest selectivity levels were observed at $25^{\circ} \mathrm{C}$, a temperature similar to the average condition in the invaded region (the lake of the Itaipu Hydroelectric Power plant).

\section{ACKNOWLEDGEMENTS}

We thank F. Franceschi for assistance during data collection and $\mathrm{CNPq}$ for research fellowships to $\mathrm{DP}, \mathrm{AO}$, and $\mathrm{WAB}$.

\section{REFERENCES}

Aldridge, D. W.; Payne, B. S. and Miller, A. C. (1995). Oxygen consumption, nitrogenous excretion, and filtration rates of Dreissena polymorpha at acclimation temperatures between 20 and $32^{\circ} \mathrm{C}$. Canadian Journal of Fisheries and Aquatic Sciences, 52, 1761-1767.

Baker, S. M.; Levinton, J. S; Kundziel, J. P. and Shumway, S. E. (1998). Selective feeding and biodeposition by zebra mussel and their relation to changes in phytoplankton composition and seston load. Journal of Shellfish Research, 17, 1207-1213.

Barbieri, R. C. and Ostrensky, A. (2001). Camarões Marinhos. Volume I Maturação, reprodução $e$ larvicultura. Aprenda Fácil Editora. Viçosa, MG, Brasil. 225 p.

Beninger, P. G. and Lucas, A. (1984). Seasonal variations in condition, reproductive activity and gross biochemical composition of two species of adult clam reared in a common habitat: Tapes decussates L. (Jeffrey) and Tapes philippinarum (Adams and Reeve). Journal of Experimental Marine Biology and Ecology, 79, 19-37.

Berg, D. J.; Fisher, S. W. and Landrum, P. F. (1996). Clearance and processing of algal particles by zebra mussel (Dreissena polymorpha). Journal of Great Lakes Research, 22, 779-788.

Boltovskoy, D. and Cataldo, D. H. (1999). Population Dynamics of Limnoperna fortunei, an Invasive fouling mollusc, in the Lower Paran River (Argentina). Biofouling, 14, 255-263.
Bougrier, S.; Geairon, P.; Deslous-Paoli, P. M.; Bacher, C. and Jonquières, G. (1995). Allometric relationships and effects of temperature on clearance and oxygen consumption rates of Crassostrea gigas (Thunberg) Aquaculture, 134, 143-15.

Cataldo, D.; Boltovskoy, D.; Marini, V. and Correa, N. (2002). Limitantes de Limnoperna fortunei en la cuenca del Plata: la predación por peces. Apresentado na: "Tercera jornada sobre conservación de la fauna íctica en el río Uruguay" Organizada por la Comisión Administradora de Río Uruguay. Abril de 2002, Paysandu Uruguai..

Coughlan, J. (1969). The estimation of filtering rate from the clearance of suspensions Marine Biology, 2, 356-358.

Darrigran, G. and Pastorino, G. (1995). The recent introduction of a freshwater Asiatic bivalve, Limnoperna fortunei (Mytilidae) into South America. The Veliger, 38, 171-175.

Darrigran, G.; Martin, S. M.; Gullo, B. and Armendariz, L. (1998). Macroinvertebrates associated with Limnoperna fortunei (Dunker, 1857) (Bivalvia, Mytilidae) in Rio de la Plata, Argentina. Hydrobiologia, 367, 223-230.

Fanslow, D. L.; Nalepa, T. F. and Lang, G. A. (1995). Filtration Rates of the Zebra Mussel (Dreissena polymorpha) on Natural Seston from Saginaw Bay, Lake Huron. Journal of Great Lakes Research, 21, 489-500.

Higgins, P. J. (1980). Effects of food availability on the valve movements and feeding behavior of juvenile Crassostrea virginica (Gmelin). II Feeding rates and behavior. Journal of Experimental Marine Biology and Ecology, 46, 17-27.

Horgan, M. J. and Mills, E. L. (1997). Clearance rates and filtering activity of zebra mussel (Dreissena polymorpha): implications for freshwater lakes. Canadian Journal of Fisheries and Aquatic Sciences, $54,249-255$.

Laing, I. (2004). Filtration of king scallops (Pecten maximus). Aquaculture, 240, 369-384..

Lei, J.; Payne, B. S. and Wang, S. Y. (1996). Filtration dynamics of the zebra mussel, Dreissena polymorpha. Canadian Journal of Fisheries and Aquatic Sciences, 53, 29-37.

Mgaya, Y. D. and Mercer, J. P. (1995). The effects of size grading and stocking density on growth performance of juvenile abalone, Haliotis tuberculata Linnaeus. Aquaculture, 136, 297-312.

Montaldo, L.; Oliveros, O. B.; Ezcurra de Drago, I. and Demonte, L. D. (1999). Peces del rio Parana Medio predadores de una especie invasora: Limnoperna fortunei (Bivalvia, Mytilidae). Revista de la Facultad de Bioquimica y Ciencias Biologicas de la Universidad Nacional del Litoral, 3, 85-101. 
Oliveira, M. D.; Pellegrin, L. A.; Barreto, R. R. and Xavier, I. G. (2004). Área de ocorrência do mexilhão dourado (Limnoperna fortunei) na Bacia do Alto Paraguai entre os anos de 1998 e 2004. Embrapa Documentos $64 . \quad 19 \quad$ p. www.cpap.embrapa.br/publicações/online/doc64 (acesso em 28/06/ 2005).

Porta, A. (2001). Biomarkers of contamination in coastal aquatic organisms of Rio de la Plata (Argentina). Acta Bioquimica Clinica Latinoamericana, 35, 261-271.

Reeders, H. and bij de Vaate, A. (1990). Zebra Mussels (Dreissena polymorpha): A New Perspective For Water Quality Management. Hydrobiologia, 200/201, 437-450.

Reeders, H. and bij de Vaate, A. (1992). Bioprocessing of polluted suspended matter from the water column by the zebra mussel (Dreissena polymorpha) Pallas Hydrobiologia, 239, 53-63.

Ricciardi, A. (1996). Limnoperna fortunei (Mytilidae): The Next Macrofouling Mussel to Invade North America? Abstract from "The Sixth International Zebra Mussel and Other Aquatic Nuisance Species Conference", McGill University, Dearborn, Michigan, March 1996.

Riisgard, H. U. (2001). On measurement of filtration rates in bivalves - the stony road to reliable data: review and interpretation. Marine Ecology Progress Series, 211, 275-291.

Savina, M. and Pouvreau, S. (2004). A comparative ecophysiological study of two infaunal filter-feeding bivalves: Paphia rhomboides and Glycymeris glycymeris Aquaculture, 239, 289-306.

Statsoft, Inc. (2003). STATISTICA (data analysis software system) versão 6.0. www.statsoft.com.

Sylvester, F.; Dorado, J.; Boltovskoy, D.; Juarez, A. and Cataldo, D. (2005). Filtration rates of the invasive pest bivalve Limnoperna fortunei as a function of size and temperature. Hydrobiologia, 534, 71-80.

Vanderploeg, H. A.; Liebig, J.A.; Carmichael, W. W.; Agy, M. A.; Johengen, T.H.; Fahnenstiel, G. L. and Nalepa T. F. (2001). Zebra mussel (Dreissena polymorpha) selective filtration promoted toxic Microcystis blooms in Saginaw Bay (Lake Huron) and Lake Erie. Canadian Journal of Fisheries and Aquatic Sciences, 58, 1208-1221.

Von Rückert, G.; Campos, M. C. S. and Rolla, M. E. (2004) Alimentação de Limnoperna fortunei (Dunker 1857): taxas de filtração com ênfase ao uso de Cyanobacteria Acta Scientiarum. Biological Sciences, 26, 421-429.

Ward, J. E. and Shumway, S. E. (2004). Separating the grain from the chaff: particle selection in suspension and deposit-feeding bivalves. Journal of Experimental Marine Biology and Ecology, 300, 83130.

Received: August 10, 2006; Revised: July 31, 2007; Accepted: June 16, 2008. 